\title{
Comparative Evaluation of Effect of Excessive Adhesive Flash Formed from Two Orthodontic Adhesives on Clinical Periodontal Status of Patients Undergoing Fixed Orthodontic Appliance Therapy
}

\author{
Kritika Pankaj Suroliya ${ }^{1}$, Priyanka Niranjane ${ }^{2}$, Ranjit Haridas Kamble³, Murtaza Shabbir \\ Hussain $^{4}$, Saurabh Hemant Shingnapurkar5, Pallavi Sachin Daigavane ${ }^{6}$, Zoher Esmail Merchant ${ }^{7}$ \\ 1,5 Suyog Dental Clinic, Mumbai, Maharashtra, India. 2, 3,6,7 Department of Orthodontics, \\ Sharad Pawar Dental College, Wardha, Maharashtra, India. ${ }^{4}$ Department of \\ Prosthodontics, Yenepoya Dental College, Mangalore, Karnataka, India.
}

\section{ABSTRACT}

\section{BACKGROUND}

Increased accumulation of dental plaque and inflammatory response during treatment is due to the appearance of new retentive places around the components of fixed appliances attached to the teeth. During bonding procedures, there is certain amount of adhesive left on the tooth surface invariably around the margins between bracket and enamel interface called excessive adhesive flash (EAF), which may act as a plaque retentive area. We wanted to evaluate and compare the effect of EAF formed from two different orthodontic bonding adhesives on clinical periodontal status of patients undergoing fixed orthodontic appliance therapy.

\section{METHODS}

20 patients indicated for treatment with fixed stainless steel preadjusted edgewise appliance were selected for the study. A split mouth design was followed where each patient's teeth were divided into 2 groups; Group A: Teeth of right side bonded with non-tooth coloured orthodontic adhesive resin (Transbond XT Plus) $-1^{\text {st }}$ and $4^{\text {th }}$ quadrants; Group B: Teeth of left side bonded with tooth-coloured orthodontic adhesive resin (Transbond XT) - $2^{\text {nd }}$ and $3^{\text {rd }}$ quadrants. Clinical periodontal status was assessed by measuring Muhlemann modified papillary bleeding index, Turesky Gilmore Glickman modification of Quigley Hein Plaque Index, and a modification of the Orthodontic Plaque Index, before bonding $\left(\mathrm{T}_{0}\right)$ and 1 week after bonding the appliance (T1).

\section{RESULTS}

Readings at $\mathrm{T}_{1}$ had significantly increased compared to $\mathrm{T}_{0}$ indicating increased plaque retention. However, difference between the indices for both groups at $\mathrm{T}_{1}$ was not statistically significant.

\section{CONCLUSIONS}

The excessive adhesive flash is a site for increased plaque accumulation, irrespective of the composite being tooth coloured or non-tooth coloured.
Corresponding Author: Dr. Kritika Pankaj Suroliya, Sapphire Heights, Lokhandwala Township, Kandivali East, Mumbai - 400101, Maharashtra, India. E-mail: kritikasuroliya@gmail.com

DOI: $10.14260 /$ jemds/2021/529

How to Cite This Article: Suroliya KP, Niranjane $P$, Kamble RH, et al. Comparative evaluation of effect of excessive adhesive flash (EAF) formed from two orthodontic adhesives on clinical periodontal status of patients undergoing fixed orthodontic appliance therapy. J Evolution Med Dent Sci 2021;10(32):25822586, DOI: $10.14260 /$ jemds/2021/529

Submission 21-11-2020,

Peer Review 06-06-2021,

Acceptance 12-06-2021

Published 09-08-2021.

Copyright (C) 2021 Kritika Pankaj Suroliya et al. This is an open access article distributed under Creative Commons Attribution License [Attribution 4.0 International (CC BY 4.0)]

\section{KEY WORDS}

EAF, Adhesives, Split Mouth 


\section{BACKGROUND}

The development of dental plaque has been analogous with various environmental and individual factors including diet composition, oral hygiene, fluoride exposure, the quality of saliva, composition of the oral microflora, and immune factors. ${ }^{1}$ Fixed or removable orthodontic appliances also hinder the maintenance of oral hygiene, leading to plaque accumulation. ${ }^{1}$ During orthodontic therapy with fixed appliances, inflammatory reaction of gingival tissue is a frequent observation. ${ }^{2}$ It has been noted that the main factor for an increased accumulation of dental plaque and inflammatory response is the appearance of new retentive areas around the components of fixed appliances attached to the teeth. ${ }^{2}$

Bonding of brackets present a major progress in orthodontics after decades of usage of multibanded fixed appliances. ${ }^{2}$ However, these changes in the design of fixed appliances did not reduce much plaque accumulation around the brackets, making this problem persistent and very actual in fixed orthodontics. ${ }^{2}$ During bonding procedures, a certain amount of adhesive is left on the tooth surface invariably, around the margin between the bracket and enamel interface. This is called excessive adhesive flash (EAF). ${ }^{3}$ If the excess adhesive is not removed, it can occasionally act as a mechanical irritation to the gingiva, particularly on teeth where distance from bracket pad to gingiva is less. ${ }^{4}$

Composite resin adhesive materials are ideally preferred in orthodontics because of their superior bonding properties and ease of working. ${ }^{3}$ With the introduction of light cured composite materials, clinicians are able to remove EAF more conveniently while it is still soft, prior to setting. ${ }^{4}$ These composite adhesive materials may be tooth-coloured or nontooth coloured. ${ }^{4}$ Numerous studies have evaluated the effect of fixed orthodontic appliances on microbial flora and periodontal status, but hardly any studies have evaluated excessive adhesive flash as an additional factor.

The purpose of this study was to evaluate and compare the effect of excessive adhesive flash (EAF) formed from two different orthodontic bonding adhesives on the clinical periodontal status of patients undergoing fixed orthodontic appliance therapy.

\section{METHODS}

The study was conducted in the Department of Orthodontics and Dentofacial Orthopaedics of Sharad Pawar Dental College, Wardha. A prospective observational study was conducted over a period of 3 months from January 2019 to March 2019 on a total of 20 patients (sample size determined using
Dahlberg's formula) who were indicated for treatment with fixed stainless steel preadjusted edgewise appliance and were selected from the outpatient department based on the following inclusion criteria -

1. Patients between 15 - 25 years of age.

2. Patients with good general health.

3. Patients with good periodontal health and without severe gingivitis or periodontitis, with adequate alveolar bone support.

4. Patients devoid of any systemic diseases, systemic diseases having oral manifestations or patients on antibiotics having effects on oral cavity.

5. Patients not using any mouth rinses in the past 3 months.

6. Patients with no history of hypersensitivity to the materials being used.

Patients with poor gingival and periodontal health, history of systemic diseases, craniofacial deformities, prosthesis, deleterious habits and history of antibiotic medication in the past 3 months were excluded from the study.

For each of these 20 patients, a split mouth design was followed uniformly where the patient's teeth were divided into two groups based on the orthodontic adhesive being used;

- Group A - All the teeth of the right side bonded with nontooth coloured orthodontic adhesive resin (Transbond XT Plus) $-1^{\text {st }}$ and $4^{\text {th }}$ quadrants.

- Group B - All the teeth of the left side bonded with tooth coloured orthodontic adhesive resin (Transbond XT) - $2^{\text {nd }}$ and $3^{\text {rd }}$ quadrants.

After approval from the Institutional Ethical Committee, written informed consent was obtained from each of these patients, and the procedure was explained in their vernacular language. Before beginning the treatment, and at every visit, patients were given oral hygiene instructions. Verbal instructions and physical demonstrations were provided on how to carry out effective oral hygiene close to the brackets and ligatures. Patients were asked to refrain from eating or drinking or performing any oral hygiene measures, for two hours before recording indices. Selected teeth for sampling were isolated with cotton rolls and dried, appropriate disclosing agent was administered for visualisation of plaque, and clinical periodontal status was assessed on the index teeth, using Turesky Gilmore Glickman modification of Quigley Hein Plaque Index, ${ }^{5}$ Muhlemann modified papillary bleeding index ${ }^{6}$ and a modification of Orthodontic Plaque Index by Beberhold. ${ }^{7}$ These readings were termed as $\mathrm{T}_{0}$.

The appliance bonding procedures were then carried out using non-tooth coloured orthodontic adhesive resin for the maxillary and mandibular right quadrants, and tooth coloured orthodontic adhesive resin for the maxillary and mandibular left quadrants, while maintaining proper isolation. The placement of appliances was done by a single operator for all the patients to avoid interoperator bias.

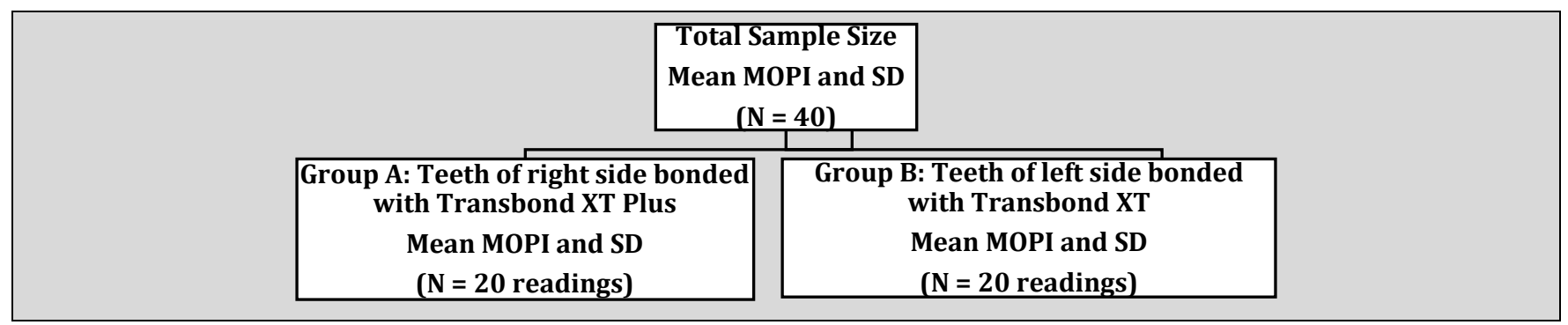


After one - week, clinical periodontal status was assessed on the teeth surfaces on the same sites, and this reading was termed as $\mathrm{T}_{1}$. Such an interval had been chosen in accordance with the assumption that there will be sufficient colonization of bacteria around the surface of the orthodontic adhesive, to produce discernible changes in the gingiva

\section{Statistical Analysis}

Statistical analysis was done by using descriptive and inferential statistics using student's paired and unpaired t test using SPSS 22.0 version software with $\mathrm{P}<0.05$ considered as level of significance and $95 \% \mathrm{CI}$ for mean difference.
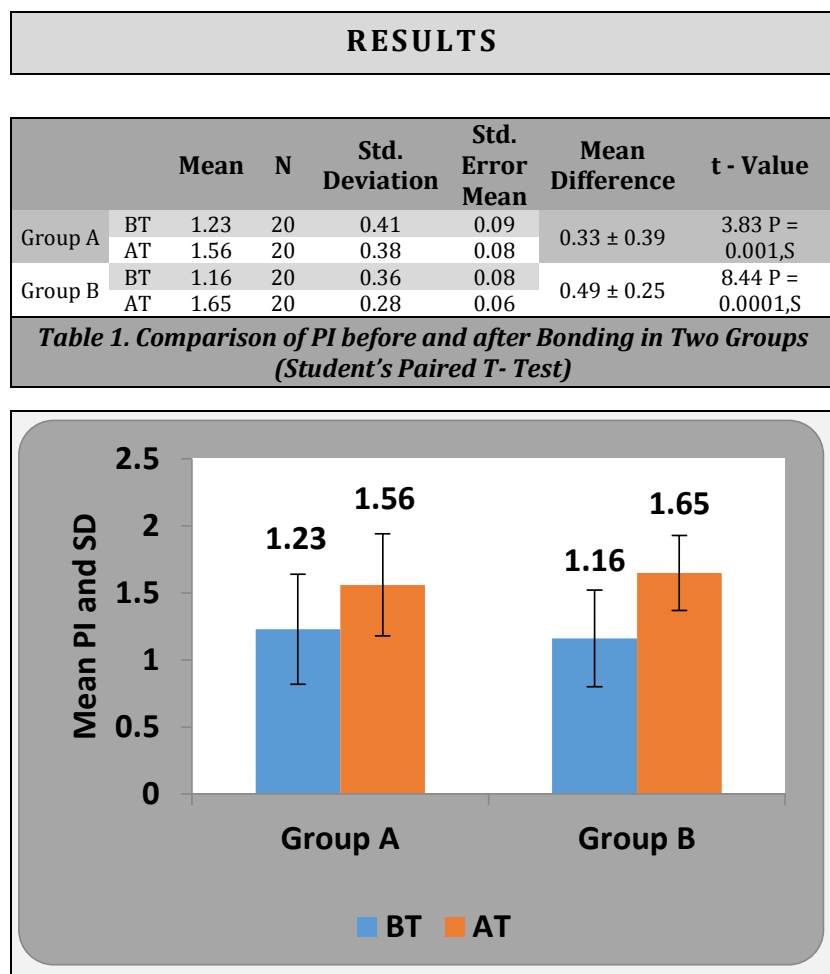

Graph 1. Comparison of PI before and after Bonding

\begin{tabular}{|cccccccc|}
\hline & & Mean & N & $\begin{array}{c}\text { Std. } \\
\text { Deviation }\end{array}$ & $\begin{array}{c}\text { Std. } \\
\text { Error } \\
\text { Mean }\end{array}$ & $\begin{array}{c}\text { Mean } \\
\text { Difference }\end{array}$ & t - Value \\
Group & BT & 0.98 & 20 & 0.32 & 0.07 & $0.15 \pm 0.27$ & $2.47 \mathrm{P}=$ \\
A & AT & 1.14 & 20 & 0.37 & 0.08 & & $0.023, \mathrm{~S}$ \\
Group & BT & 0.94 & 20 & 0.35 & 0.07 & 4.21 \\
B & AT & 1.26 & 20 & 0.40 & 0.09 & $0.32 \pm 0.34$ & $\begin{array}{c}\mathrm{P}= \\
0.0001, \mathrm{~S}\end{array}$ \\
\hline \multicolumn{7}{|c|}{ Table 2. Comparison of PBI before and after Bonding in Two Groups } \\
(Student's Paired T Test)
\end{tabular}

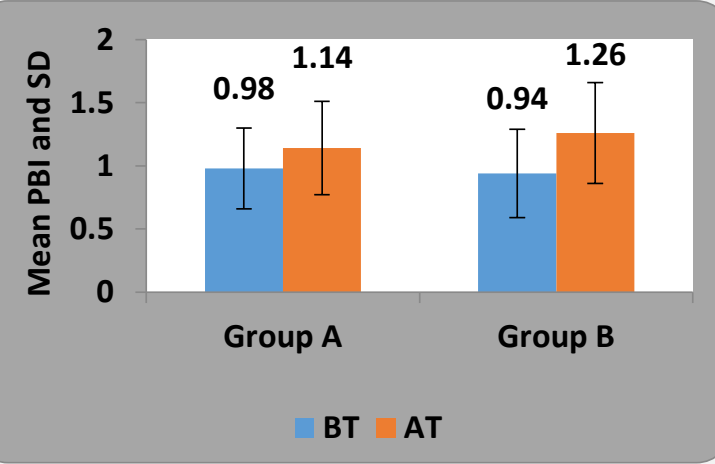

Graph 2. Comparison of PBI before and after Bonding in Two Groups
In both the groups of the examined teeth, after the attachment of bands and brackets, the values of plaque and gingival indices showed an increase during the next periods.

The post bonding increase in the values of these indices was found to be statistically significant for both groups. The values of all the three indices, were found to be highest at $T_{1}$ for Group B. However, the difference between the indices for both groups at $\mathrm{T}_{1}$ was not found to be statistically significant.

\begin{tabular}{|ccccccc|}
\hline $\begin{array}{c}\text { Indices } \\
\text { used }\end{array}$ & Group & $\mathbf{N}$ & Mean & $\begin{array}{c}\text { Std. } \\
\text { Deviation }\end{array}$ & $\begin{array}{c}\text { Std. } \\
\text { Error } \\
\text { Mean }\end{array}$ & $\begin{array}{c}\text { t - } \\
\text { Value }\end{array}$ \\
PI & Group A & 20 & 0.33 & 0.39 & 0.08 & $1.47 \mathrm{P}=$ \\
& Group B & 20 & 0.49 & 0.25 & 0.05 & $0.14, \mathrm{NS}$ \\
PBI & Group A & 20 & 0.15 & 0.27 & 0.06 & $1.71 \mathrm{P}=$ \\
& Group B & 20 & 0.32 & 0.34 & 0.07 & $0.09, \mathrm{NS}$ \\
MOPI & Group A & 20 & 2.95 & 0.82 & 0.18 & $1.88 \mathrm{P}=$ \\
& Group B & 20 & 3.40 & 0.68 & 0.15 & $0.06, \mathrm{NS}$ \\
\hline \multicolumn{7}{|c|}{ Table 3. Comparison of Mean Difference of Indices in Two Groups } \\
(Student's Unpaired T Test)
\end{tabular}

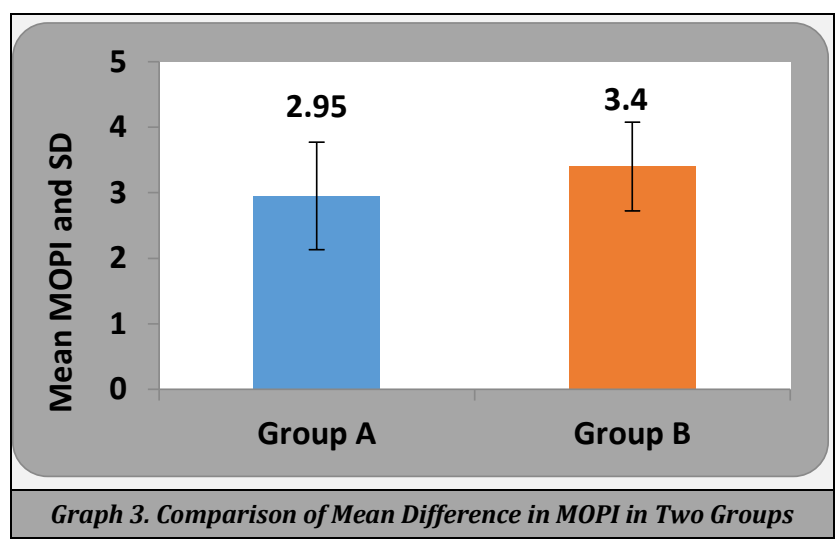

\section{DISCUSSION}

Literature is abundant with studies proving that fixed orthodontic appliances increase plaque accumulation, bacterial colonization, and resultant enamel decalcification. Various studies have been conducted elaborating on bacterial colonization with regard to orthodontic adhesives, however very few studies have assessed the effect of these adhesives on clinical periodontal and gingival status of patients. Also, not many studies have been done with respect to excessive adhesive flash (EAF) and the associated clinical and microbiological changes that occur around it.

In the present study, a split mouth design was followed to test the effect of excessive adhesive flash (EAF) formed from two different types of orthodontic adhesives on the clinical periodontal status of 20 patients. This was done by measuring plaque and gingival indices at two occasions which were one week apart. The second measurement (T1) was performed one week after bonding (T0) because Sukontapatipark ${ }^{8}$ et al. detected abundant plaque on bonded teeth within one week. The present study revealed that there was a significant increase in plaque accumulation at the bracket - adhesive enamel interface at $\mathrm{T}_{1}$ around the flash formed from both, tooth coloured adhesive (Transbond XT) and non-tooth coloured adhesive (Transbond XT Plus). The plaque accumulation was more around tooth coloured orthodontic adhesive. Matasa et al. ${ }^{9}$ have stated that composites used as 
orthodontic direct bonding adhesives have a polymeric matrix that can host and nurture a variety of aerobic and anaerobic microorganisms acting alone or in combination. This could be a reason for increased plaque accumulation around the excessive adhesive flash. However, the difference between the amount of plaque accumulation around tooth coloured and non-tooth coloured orthodontic adhesives at $\mathrm{T}_{1}$, was not found to be statistically significant.

Fixed orthodontic appliances create new retention areas suitable for bacterial colonization. ${ }^{10-12}$ A certain deterioration of the gingival and periodontal status has been reported in orthodontically treated children. ${ }^{13,14}$ Glans et al.15 reported that the gingival bleeding index improved significantly from 12 weeks after bonding to debonding in the patients with crowded dentitions. Bollen et al. ${ }^{16}$ systematically reviewed and compared contemporary orthodontic treatment with no intervention, by means of evaluating periodontal outcomes measured after end of treatment. It was found that orthodontic therapy was associated with 0.03 millimetres of gingival recession, $0.13 \mathrm{~mm}$ of alveolar bone loss and $0.23 \mathrm{~mm}$ of increased pocket depth, suggesting that orthodontic therapy resulted in small detrimental effects to the periodontium.

Naranjo et al. ${ }^{17}$ investigated changes in subgingival microbiota and clinical parameters before and after bracket placement in 30 samples, and found that bracket placement influences the accumulation of plaque and the colonization of important periodontopathic and superinfecting bacteria, resulting in more inflammation and bleeding.

Ristic et al. ${ }^{2}$ carried out a prospective longitudinal self controlled study on 32 adolescents undergoing fixed orthodontic treatment. Dental plaque accumulation, gingival inflammation and pocket probing depth were measured at the mesio - vestibular angle of the examined group of teeth followed by collection of subgingival dental plaque samples in the same points, prior to the placement of fixed appliances and 1,3 and 6 months after the beginning of orthodontic treatment. It was found that treatment with fixed appliances in adolescents may transitionally increase the values of all periodontal indices and stimulate the growth of periodonto pathogenic bacteria, but without destructive effects on deep periodontal tissues.

Carrillo et al. conducted a study in 34 patients to identify changes in the oral environment with clinical, salivary and bacterial risk markers after placement of fixed orthodontic appliances on permanent dentition. It was noted that orthodontic treatment changes the oral environmental factors, promotes an increase in stimulated flow rate, buffer capacity and salivary ph. Bacterial levels increased slightly after 1 month of treatment, but without statistical significance.

\section{CONCLUSIONS}

The present results confirm the fact that, in orthodontic patients, treatment with fixed appliances increases the values of periodontal indices. The excessive adhesive flash is a site for increased plaque accumulation, irrespective of the composite being tooth coloured or non-tooth coloured. Nevertheless, as the risk of periodontal damage exists, it is necessary to provide continuous control of orthodontic patients, good oral hygiene instruction and constant motivation during the whole period of fixed appliance therapy.
Data sharing statement provided by the authors is available with the full text of this article at jemds.com.

Financial or other competing interests: None.

Disclosure forms provided by the authors are available with the full text of this article at jemds.com.

\section{REFERENCES}

[1] Turkkahraman H, Sayın MO, Bozkurt FY, et al. Archwire ligation techniques, microbial colonization and periodontal status in orthodontically treated patients. Angle Orthod 2005;75(2):231-6.

[2] Ristic M, Svabic MV, Sasic M, et al. Clinical and microbiological effects of fixed orthodontic appliances on periodontal tissues in adolescents. Orthod Craniofac Res 2007;10(4):187-95.

[3] Ho CSF, Ming Y, Foong KWC, et al. Streptococcus mutans forms xylitol-resistant biofilm on excess adhesive flash in novel ex-vivo orthodontic bracket model. Am J Orthod Dentofacial Orthop 2017;151(4):669-77.

[4] Armstrong D, Shen G, Petocz P, et al. Excess adhesive flash upon bracket placement. A typodont study comparing APC PLUS and transbond XT. Angle Orthod 2007;77(6):1101-8.

[5] Loe H. The gingival index, the plaque index and the retention index systems. J Periodontol 1967;38(suppl 6):610-16.

[6] Greenstein G. The role of bleeding upon probing in the diagnosis of periodontal disease. A literature review. J Periodontol 1984;55(12):684-8.

[7] Beberhold K, Sachse-Kulp A, Schwestka-Polly R, et al. The orthodontic plaque index: an oral hygiene index for patients with multibracket appliances. Orthodontics (Chic) 2012;13(1):94-9.

[8] Sukontapatipark W, El-Agroudi MA, Selliseth NJ, et al. Bacterial colonization associated with fixed orthodontic appliances. A scanning electron microscopy study. Eur J Orthod 2001;23(5):475-84.

[9] Matasa CG. Microbial attack of orthodontic adhesives. Am J Orthod Dentofacial Orthop 1995;108(2):132-41.

[10] Forsberg CM, Brattstrom V, Malmberg E, et al. Ligature wires and elastomeric rings: two methods of ligation and their association with microbial colonization of Streptococcus mutans and lactobacilli. Eur J Orthod 1991;13(5):416-20.

[11] Balenseifen JW, Madonia JV. Study of dental plaque in orthodontic patients. J Dent Res 1970;49(2):320-4.

[12] Diamanti-Kipioti A, Gusberti FA, Lang NP. Clinical and microbiological effects of fixed orthodontic appliances. J Clin Periodontol 1987;14(6):326-33.

[13] Chang HS, Walsh LJ, Freer TJ. The effect of orthodontic treatment on salivary flow, $\mathrm{pH}$, buffer capacity and levels of mutans streptococci and lactobacilli. Aust Orthod J 1999;15(4):229-34.

[14] Lundstrom F, Hamp SE. Effect of oral hygiene education on children with and without subsequent orthodontic treatment. Scand J Dent Res 1980;88(1):53-9.

[15] Glans R, Larsson E, Ogaard B. Longitudinal changes in gingival condition in crowded and noncrowded dentitions subjected to fixed orthodontic treatment. Am J Orthod Dentofacial Orthop 2003;124(6):679-82. 
[16] Bollen AM, Cunha-Cruz J, Bakko DW, et al. The effects of orthodontic therapy on periodontal health: a systematic review of controlled evidence. J Am Dent Assoc 2008;139(4):413-22.
[17] Naranjo AA, Triviño ML, Jaramillo A, et al. Changes in the subgingival microbiota and periodontal parameters before and 3 months after bracket placement. Am J Orthod Dentofacial Orthop 2006;130(3):275.e17-22. 